\title{
Development and validation of a health educational booklet
}

Water safety and drowning prevention

Noor Hamzani Farizan

Department of Community Health, University Putra Malaysia, Serdang, Malaysia and

Department of Community Health, Universiti Kebangsaan Malaysia Medical Centre, Kuala Lumpur, Malaysia

Rosnah Sutan and Rozita Hod

Department of Community Health, Universiti Kebangsaan Malaysia Medical Centre, Kuala Lumpur, Malaysia, and

Kulanthayan KC Mani

Department of Community Health,

Faculty of Medicine and Health Sciences, Universiti Putra Malaysia,

Serdang, Malaysia

\begin{abstract}
Purpose - This study aimed to develop and validate a health education booklet (Be SAFE booklet) as a guide to improving knowledge, attitude, and practice toward drowning prevention and water safety among parents of primary school children in a local community in Selangor.

Design/methodology/approach - This methodological study was conducted in two phases: the development of the content, and validation of the educational material. Booklet development involved content survey and design development. These steps consisted of a content analysis method, information from current literature, document analysis from the stakeholder, and input from parents or guardians and children. The validation by nine panel experts and 15 parents/guardians involved both review, content validity, and face validity.

Findings - The booklet was developed by emphasizing on four main aspects related to drowning prevention and water safety; namely, supervision, alertness, first aid, and education. The assessment rated by the content validity index (CVI), resulted in an I-CVI ranging from 0.78 to 1 and S-CVI of 0.94 ; the face validity achieved a level of agreement with an average of 94 percent. The results indicated that the Be SAFE booklet was validated and could be considered useful in helping to promote drowning prevention and water safety among primary school pupils' parents. Originality/value - This article contributed ideas for the concept and aspect of health messages to be incorporated into health education materials for drowning prevention and water safety.
\end{abstract}

Keywords Drowning prevention, Water safety information, Content validity, Health education,

Health promotion, Parents

Paper type Research paper

\section{Introduction}

Parental guardianship is the most important and effective means to protect children from many injury-related deaths including drowning [1-4]. Several studies demonstrated parental

(C) Noor Hamzani Farizan, Rosnah Sutan, Rozita Hod and Kulanthayan KC Mani. Published in Journal of Health Research. Published by Emerald Publishing Limited. This article is published under the Creative Commons Attribution (CC BY 4.0) licence. Anyone may reproduce, distribute, translate and create derivative works of this article (for both commercial and non-commercial purposes), subject to full attribution to the original publication and authors. The full terms of this licence may be seen at http://creativecommons.org/ licences/by/4.0/legalcode

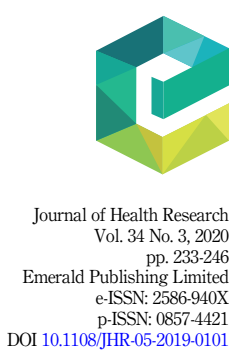


JHR

34,3

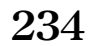

factors in childhood injuries focusing on parental knowledge, perceptions, attitudes, supervision, etc. [1, 3-6]. Improving the understanding of drowning strategies and preventive measures includes increasing parents' knowledge of water safety to help regulate the risk of child drowning and the ability to identify risk factors in most child drowning incidents. Inadequate caregiver supervision and uncertainty regarding responsibilities with regards to how to protect children when in the water, put children at the risk of drowning [6]. Providing water safety knowledge to parents results in improving awareness of child water safety, and increases the understanding of the circumstances surrounding toddler drowning $[7,8]$.

Currently, in Malaysia, the reality about drowning children is still one of ignorance regarding the community and its habits. Statistics show children aged under 18 years encounter almost 45 percent of total drowning deaths with the number drowned at approximately 500 a year [9]. Selangor reported having the highest mortality drowning rate in Peninsular Malaysia as recorded by the Department of Fire and Rescue (statistic data from year the 2012-2015) [10]. Despite various approaches to drowning prevention, Malaysia is still way behind other nations. The current scenario with existing drowning prevention efforts in Malaysia involves several relevant authorities, but current regulations and government projects focus more on a central blueprint, and lack adequate relevant information on water safety for local everyday situations [9].

Findings from previous studies developed a core message on the need to promote water safety education for parents and guardians, and suggested initiatives emphasized knowledge of supervision, basic swimming skills, learning first-aid methods, the necessity for caution when estimating risk, and the ability to cope with open water conditions, etc. [8, 11-15]. Thus, this study aims to develop and validate a health educational booklet (Be SAFE booklet) as a guide to improving knowledge, attitude, and practice toward drowning prevention and water safety among parents of primary school children in a local community in Selangor. The booklet will create learning materials that can be used as an educational strategy, and is designed to provide knowledge and information on drowning risk, drowning prevention, and water safety. It is also expected to enhance parental or guardian skills and competencies in water safety and to increase understanding of drowning issues.

\section{Methodology}

The methodological steps involved in this study consisted of two phases based on the steps shown in the schematic diagram presented in Figure 1.

\section{Phase I: Development of the health education booklet \\ Step 1: Content construction}

Needs analysis. Prior to the development of the booklet, a situational analysis and needs assessment was conducted to get an overview of the drowning situation and determine the purpose of developing the health educational booklet. The questionnaire was used to examine the current situation with regards to the prevalence of knowledge, attitude, and practice on drowning prevention and water safety among parents of primary school children [16]. In addition, parents of primary school children were selected by convenience sampling and were interviewed for their opinions on drowning prevention and water safety. The interview process was conducted until reflections on all questions were recorded [17].

In addition, an exploration of basic water safety awareness among children whose parents participated in the study was conducted. The children were invited to complete a quiz type questionnaire which consisted of ten basic questions on water safety with six multiple-choice questions and four True/False questions adopted from the Royal Lifesaving Society UK and Safe Kids Worldwide information. The quiz session was written in local languages (Bahasa Malaysia), and was conducted in the classroom with permission from the school 


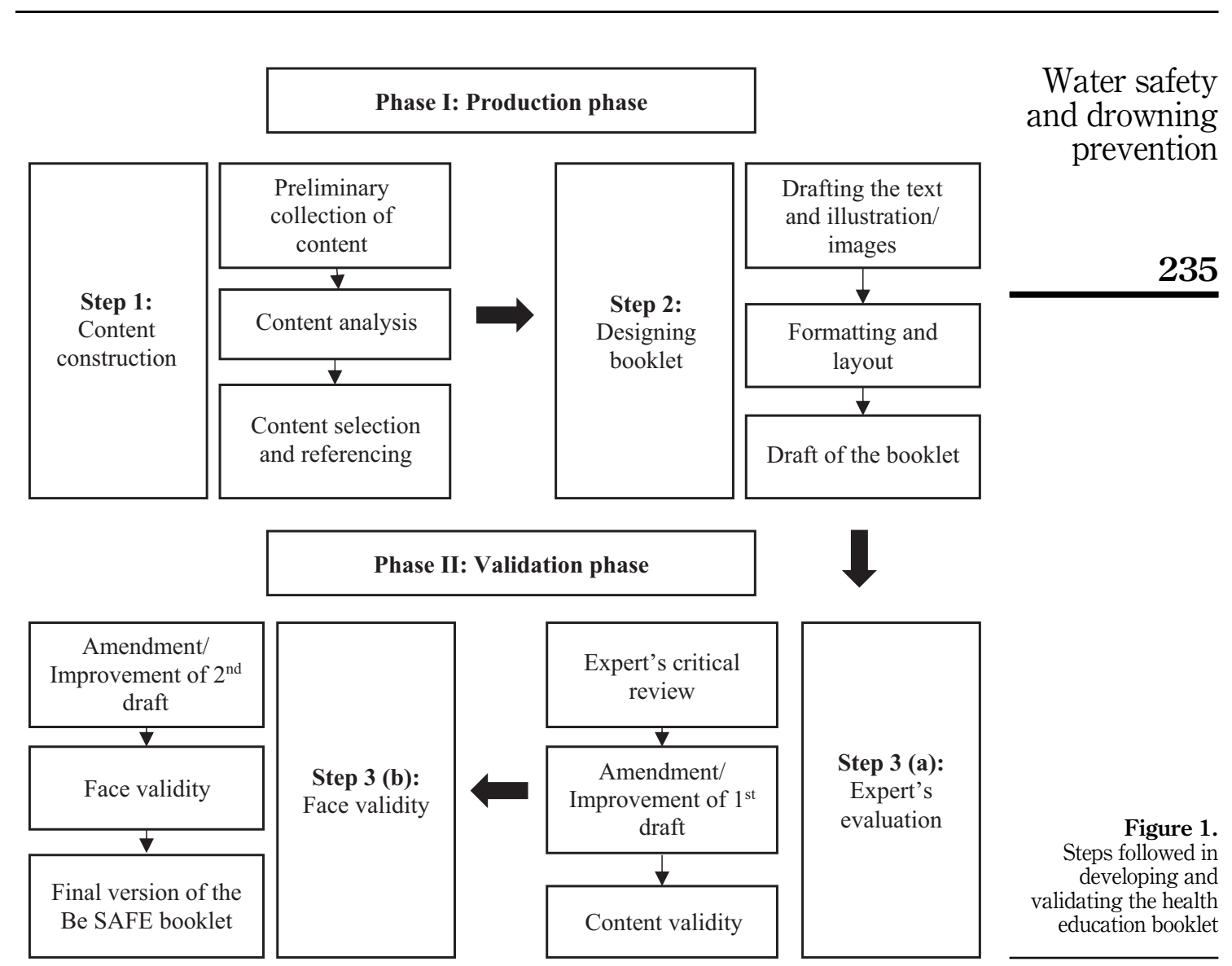

administrator. Quizzes as conducted in other studies were found useful in providing information on basic knowledge and awareness $[18,19]$. Findings from this quiz provided information on the need for parents to educate their children on drowning prevention and water safety.

Content survey. A literature review and document analysis were conducted for the initial ideas, framework, and justification of the selection of the topic for the booklet. The search strategies for the literature involved an electronic source (online database), printed materials, and gray literature. A search for online articles related to approaches and strategies in drowning prevention and water safety was conducted using the keywords: drowning prevention, water safety, childhood drowning, drowning prevention intervention, and drowning risk. Other existing and related publications such as gray material (national drowning report and fire department statistics) and printed materials (pamphlets, factsheets, guidelines, etc.) were analyzed to provide the key findings of health messages to be delivered to the target group. The existing and related publications focusing on the strategies of drowning preventive measures and water safety competencies were reviewed to provide the key findings of health messages to be delivered to the target group.

Drowning preventive measures demand a multi-sectorial approach and cooperation from various agencies. In Malaysia, the Water Activity Safety Council (WASC) was established as a representative of several sectors (government, NGOs, private sectors, etc.) with objectives to 
JHR

34,3 promote water safety awareness in a holistic and comprehensive manner covering all segments of society, as well as to introduce national water safety standards. Thus, input from WASC was gathered on their existing drowning prevention efforts, roles, data, experiences, and approaches to addressing drowning issues in Malaysia.

Content selection and referencing. The literature review on drowning-prevention strategies, opinions extracted from the informal interview with target groups, a summary of the sharing information session from multi-sectorial stakeholders, and result of the awareness level on children's water safety provided ideas on the important aspects to be highlighted on drowning prevention. Data triangulation was applied to assure the validity of content through the use of a variety of methods to collect data on the same topic, which involved different types of samples as well as methods of data collection [20]. However, the purpose of triangulation is not necessarily to cross-validate data but rather to capture different dimensions of the content related to drowning prevention and water safety. All relevant information that might apply in the development of the booklet was compiled, gathered, and categorized into the following concepts: supervision, alertness, first aid, and education.

\section{Step 2: Designing the booklet}

Drafting and formatting. The draft booklet was arranged with consideration of a suitable local language (Bahasa Malaysia), appropriate illustrations, and an attractive layout to ensure it was readable, understandable, effective, and culturally relevant, to ensure drowning prevention and water safety.

\section{Step 3: Evaluation}

Expert's critical review. Nine panel experts from various relevant backgrounds related to drowning prevention and water safety were invited to evaluate and validate the booklet. A public health lecturer, a clinician, a representative of the Life-Saving Society Malaysia (LSSM), a professional swimming instructor, a senior officer of the Fire and Rescue Department Malaysia, and Health Education Officer were involved in this phase. The panel members were selected based on their background expertise related to the study. For example, the public health lecturer was an expert in health promotion and the clinician had over 10 years' experience in the medical field and was familiar with the injuries related to drowning. The representative of the Life LSSM had to work with the agencies that are actively involved in drowning prevention and water safety in this country. The professional swimming instructor provided an actual situation related to drowning and many tips on the water safety concept. The representative from the Fire and Rescue Department Malaysia was an expert in rescue and safety operations and had wide experience of many drowning incidents. Finally, the involvement of the Health Education Officer was beneficial in providing input for the health educational booklet to be used as an intervention instrument.

Content validity. The improvement of the first draft went through re-evaluation by the same panel of experts but in this round, the assessment was based on five criteria: front cover, writing style, structure and presentation, objectives, relevance, and the overall score of the booklet. The panel was given a set of modified and adopted evaluation forms from previous studies [21-23] and scores were based on a 4-point Likert scale of strongly disagree $=1$, disagree $=2$, agree $=3$, strongly agree $=4$. The content validity index (CVI) was used to indicate the agreement among the panels on the items (I-CVI) and an average of each scale (S-CVI) of the content.

Face validity. The face validation was conducted by the targeted audience for the health education booklet. Fifteen respondents were randomly selected from among the parents/ guardians of primary school children and were invited to give their comments and opinions 
on the readability, feasibility, general formatting, and presentation of the health educational booklet. The evaluation form also used the Likert scale of 1-4 and any suggestions, comments, or recommendations from the parents could be added to the booklet.

Ethical consideration. The study was approved by the Research Ethics Committee, The National University of Malaysia (UKM PPI/111/8/JEP-2016-594).

\section{Results}

Phase I: Content development

Component 1: Parent's informal interview. Twenty informants were involved in this informal or conversational interview with an age range of 23-41 years (mean $34.85 \pm 5.060$ ). Background information included mother (50 percent), father (20 percent), or guardian (30 percent) with the majority working in the government sector (85 percent). Most of the informants (85 percent) claimed that they could swim and 45 percent of them also selfreported to be trained and certified in cardiopulmonary resuscitation (CPR). The information obtained from the parents based on their views of the current status of drowning prevention efforts and strategies in Malaysia and their views of what parents can do to help is summarized in Table I and II.

Component 2: Children's water safety quiz. A total of 800 sets of water safety quiz questionnaires were distributed to children in a selected primary school in Hulu Langat with a 100 percent response rate. A total of 474 ( 59.3 percent) Standard 5 pupils (11-years old) and 326 (40.8 percent) Standard 4 pupils (10 years old) took the quiz. Most participants were Malay (97.4 percent) and female ( 6 percent). Other ethnicities included Chinese $=3$ ( 0.4 percent), Indian $=10$ (1.3 percent), and others $=8$ (1.0 percent). The student's correct responses to each item of the water safety quiz questions and summated score are shown in Table I.

From the results, the children showed good knowledge of the emergency responses as most of them (90.3 percent) knew the number to call in an emergency. They also had a good knowledge of drowning risks as most of them agreed with the risk of diving in open water or playing in floodwaters. However, they showed a low awareness of the usage of personal floatation devices (PFDs) as many of them did not know when to wear them (41.1 percent) and the actual PFDs that could protect them from drowning (45.3 percent). Alarmingly, almost half the students (40.8 percent) perceived that they could swim alone if they had taken swimming lessons and only 29.1 percent realized that they could not swim at unpatrolled beaches (no lifeguard present). In the comparison of gender, male students scored 28.5 percent and female students scored 34.9 percent correct answers from the total score of the water

\begin{tabular}{|c|c|c|c|}
\hline \multirow{2}{*}{$\begin{array}{l}\text { Item } \\
\text { code }\end{array}$} & \multirow[b]{2}{*}{ Water safety questions } & \multicolumn{2}{|c|}{$\begin{array}{l}\text { Correct } \\
\text { response }\end{array}$} \\
\hline & & $N$ & $\%$ \\
\hline Q1 & What is the only good excuse for not wearing a life jacket when you are on a boat? & 736 & 92.0 \\
\hline $\mathrm{Q} 2$ & I can swim alone if I have taken swimming lessons (True/ False) & 473 & 59.1 \\
\hline Q3 & When do you need to wear a life jacket? & 329 & 41.1 \\
\hline $\mathrm{Q} 4$ & How can you keep safe while swimming in a pool? & 632 & 79.0 \\
\hline Q5 & Which of these items will protect you from drowning? & 362 & 45.3 \\
\hline Q6 & $\begin{array}{l}\text { It is okay to dive into open water safety sites, such as a lake or a river because they are } \\
\text { deeper than pools. (True/ False) }\end{array}$ & 798 & 99.8 \\
\hline Q7 & If someone falls into the water safety and is in trouble, I should... & 200 & 25.0 \\
\hline Q8 & Number to call for an emergency is 999 (True/ False) & 722 & 90.3 \\
\hline Q9 & If there is no lifeguard at the beach, you ... & 233 & 29.1 \\
\hline Q10 & I can play with flood water safety if an adult accompanies me (True/ False) & 679 & 84.9 \\
\hline
\end{tabular}

Water safety and drowning prevention

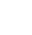




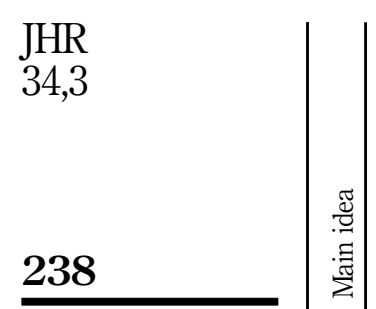

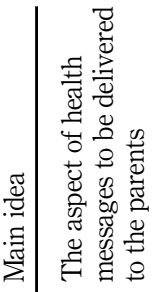

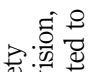

幽

屯

䒕

넝료

它芯

겅

过若

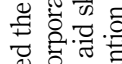

:

낭

悹

氠.范

. 용 की

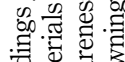

语芯总

Table II.

Sources of input for the content development of the health education booklet

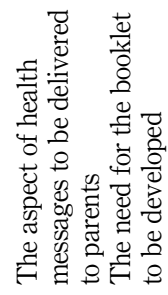

胥
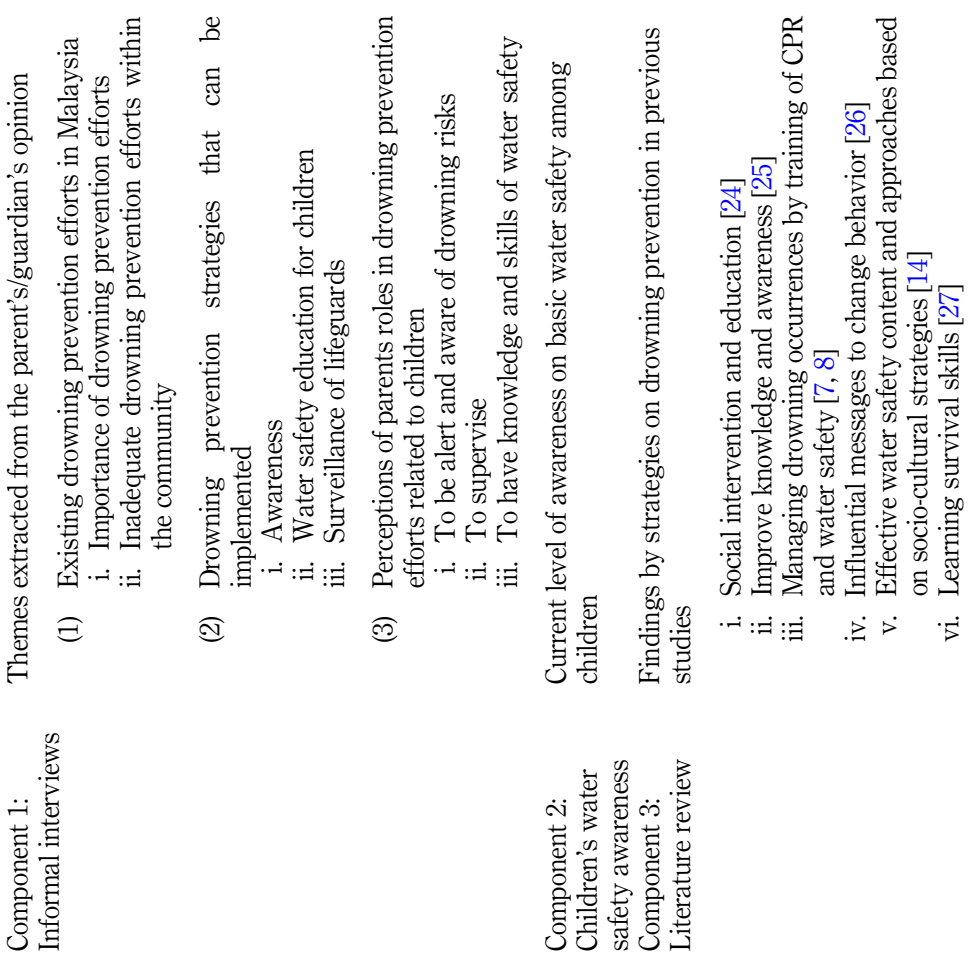


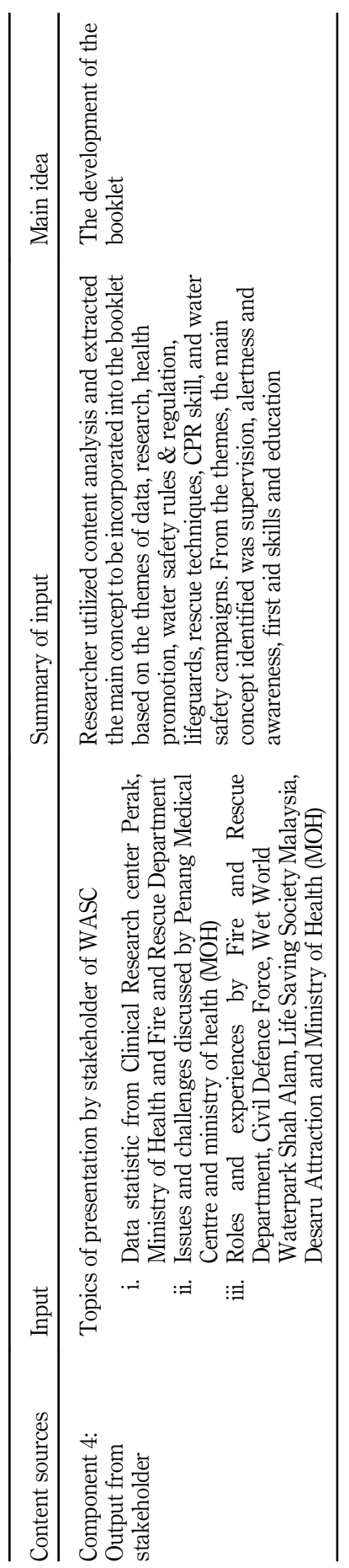

Water safety and drowning prevention

239

Table II 
JHR

34,3

safety quiz. The result of the water safety quiz showed more than half of the students (52.5 percent) had a total score below the mean score. In summary, the awareness of the children on water safety required attention, thus indicating that there is a need for increased drowning prevention and water safety messages.

Component 3: Literatures review. Literature reviews from internet-based sources (journals) and other gray sources were compiled as a summary of drowning prevention strategies (Table II).

Component 4: Output from the stakeholder of WASC. The output from the stakeholder utilized content analysis as a type of analysis and the results, the shared information from the stakeholder representative' presentation were found useful for the content of the health educational booklet. Some of the statistical data were used in the section on drowning facts in Malaysia and some shared experiences were incorporated in the myths of the drowning section. Moreover, water safety tips and rescuing techniques were used as a guide in the health educational booklet (Table II).

Table II summarized the two main ideas for the development of the booklet. The first idea, from the literature (component 1) and output from the stakeholder (component 2) helped the researcher to identify the aspect of health messages to be delivered to the parents. The second idea, from component 3 (informal interviews with parents) and component 4 (output on the level of children's water safety awareness) justified the need for the booklet to be developed and be used as an intervention tool to improve KAP on drowning prevention and water safety.

\section{Designing the health education booklet}

The booklet contents were organized in a framework consisting of the introduction, drowning facts in Malaysia, myths on childhood drowning, the main text on water safety and drowning prevention, a checklist of water safety, and a disclaimer. Every page was arranged with a consideration of appropriate text, formatting, and additional images or illustration in order to produce an attractive and informative booklet. The booklet was revised several times before the draft was ready for the evaluation process.

\section{Phase II: Content validation}

Expert's review and content validity. The evaluation and validation process involved a team of nine experts including a Public Health Specialist $(n=1)$, Medical Officer $(n=1)$, a representative of the LSSM $(n=1)$, professional swimming instructors $(n=2)$, Senior Fire \& Rescue Officers $(n=2)$, and Health Education Officers $(n=2)$.

The experts revised the health education booklet and rated the items using five criteria with overall ratings assessed to describe the agreement among the judges as to the adequacy and relevance of the booklet. Item level content validity index (I-CVI) calculated for individual items, ranged from 0.78 to 1.00 . Scale level content validity (S-CVI) was calculated for the completed 22 items and was found to be 0.94 . The S-CVI should have a minimum value of 0.80 to be acceptable (Table III).

\section{Face validity}

To confirm face validity, 15 parents of primary school children were invited to check on the readability, feasibility, general formatting, and presentation of the booklet. The level of agreement of the respondents was calculated for the four criteria (15 items) of the instrument using I-CVI and S-CVI/Ave values as shown in Table IV. The analyzed result shows the level of agreement among the parents was high, varying from 80.0 to 100 percent, with an S-CVI/ 
Criteria/ Items

I-CVI

A. Front cover

1. The cover is suitable and catchy

2. The title is suitable

3. The cover is in accordance with title

B. Writing style

4. The font and style is suitable

5 . The written content is clear and neat

6. The chosen font and size is appropriate

7. Line and paragraph spacing between the texts are appropriate and consistent

\section{Structure and presentation}

8. Arrangement of content is clear and attractive

9. Word structure and activities are appropriate and suitable

10. The language used is easy to understand

11. The scope of contents was sufficiently in-depth

12. The use of images coincide with the topics presented

13. Images easily attract readers

14. The information presented is scientifically correct

15. The material is socially and culturally appropriate for the proposed target audience

16. The booklet has a suitable number of pages

\section{Objectives}

17. Coincides with the target population

18. Can be circulated and executed within the community

19. Can improve knowledge, attitude and intention to practice on drowning prevention and water safety among parents
0.88

0.78

0.78

1.00

1.00

1.00

0.88

0.78

1.00

1.00

1.00

0.88

0.88

1.00

1.00

0.88

1.00

1.00

1.00

1.00

1.00

0.94

Mean

0.74
Water safety and drowning prevention

Relevance

The topics portray key aspects that need to be reinforced measures

22. The booklet addresses relevant aspects of how parents should prepare themselves with water safety skills

Scale content validity index (S-CVI/Average I-CVI)

Overall, what rating would you give this booklet? (Please give a score out of 10 )
Table III.

Content validation index scores

Average value of 94.0 percent, higher than the established minimum of 75 percent, which indicated face validity for the booklet.

Entire comments from content and face validation were considered and thoroughly discussed by the research team. The items in the content were either edited, removed, or remained unchanged after extensive discussion among the researchers. The results indicated the instrument could be considered to promote the prevention of drowning and water safety, in the context of educational activities to improve knowledge and intention to practice among parents or guardians of primary school children.

\section{Discussion}

Printed health educational information was found to be useful in improving knowledge, satisfaction, adherence to treatment, as well as to stimulate patient's self-care [28]. Health education materials such as booklets, pamphlets, and leaflets were widely used as a tool for public or patient education in a variety of health-related issues [23, 29-31]. Printed materials were found useful in changing knowledge, attitudes, and behavior but it was advised that 


\section{Criteria/ Items}

A. Front cover

1. Interesting

2. In accordance with title

6. Line and paragraph spacing between the texts is appropriate and consistent

\section{Structure and presentation}

7. Arrange set is clear and attractive

8. Word structure and activities are appropriate and suitable

9. The language used is easy to understand

10. The scope of contents was sufficiently in-depth

11. The use of images coincide with the topics presented

12. Images that easily attract readers

\section{Motives}

13. Do you understand what it is about when reading this booklet?

14. Does the booklet address the relevant aspects of how to prevent drowning and water safety?

Table IV.

15. Does the booklet indicate that you should acquire knowledge of drowning prevention and water safety?

Scale content validity index (S-CVI/Average I-CVI)
1.00

1.00

0.87

0.87

0.80

0.80

100

100

87

87

80

80

0.93

1.00

0.93

0.93

1.00

1.00

$14.13 / 15=0.94$

reliance on content and design strategy alone was not enough [32]. Printed materials such as booklets can also be shared with others and can be kept for reference and serve as useful reminders. Enhancement of other strategies such as promotional and the other additional modalities was a promising approach in increasing the effectiveness of the printed materials $[33,34]$.

Printed materials should provide adequate health-related educational information to encourage preventive behaviors, but must not be too extensive in length, because they may appear overwhelming and inhibit the recipient from reading them [35].

From the findings, results of the content analysis contributed ideas for the concept and aspect of health messages to be incorporated into the booklet emphasizing four main aspects related to drowning prevention and water safety; namely: supervision, alertness, first aid, and education. These four aspects were also used as an acronym for the booklet with $\mathrm{S}$ for 'supervise', A for 'alertness' and 'awareness', and F for 'first aid' (Be SAFE). The discussion of each aspect was as follows.

\section{Supervision (S)}

Supervision was highlighted as one of the important aspects of drowning prevention and water safety for parents/ guardians. Inadequate supervision was found to be significant in many studies [2, 4, 36-38]. Parental supervision was presented as one of the most effective injury prevention strategies that are both low in cost and socially acceptable to the community in high-income countries [37, 39-41]. To ensure the quality of supervision, recommendations call for the efficacy of these supervisory roles to be emphasized; thus, active supervision education for parents, caregivers or caretakers is needed $[1,3,39]$. In conclusion, the importance of supervision should also be continued as a whole, an integral and realistic component for all drowning prevention strategies globally. 
Alert and aware (A)

Previous studies presented the benefit of identifying hazards such as identification of rip currents, muddy banks, and turbid water and recognition of beach flag warnings [25, 27]. Awareness and alertness related to the ability to identify potential risks or hazards are vitally important for parents, guardians, or carers so they can supervise children in this area. Prevention programs or health messages that need to be delivered to parents should focus on adult supervision for children and create awareness of the dangers or risks of drowning whenever in or around water.

\section{First aid (F)}

Drowning prevention and water safety emphasize the need for the general public to have basic first aid skills as it can potentially help prevent incidents such as the effects of neardrowning [41]. First aid education in the event of drowning occurrence together with training in first aid skills should be learned by family members to help with immediate emergencies $[42,43]$. There is enough evidence that shows us the importance of parental knowledge of first aid and CPR, making the first aid component an important section of the health educational booklet.

\section{Education (E)}

Regarding education, several topics were emphasized for inclusion such as water safety education, the importance of swimming lessons, and the use of PFDs or lifejackets, environmental hazards, and safety signage. Water safety education and promoting swimming skills were revealed by many studies to have a vitally important impact as one of the drowning prevention strategies for parents or caregivers $[7,8,13]$. Wearing appropriate and insulated life jackets should be promoted as a drowning prevention strategy wherever possible [44].

\section{Evaluation of validity and reliability of the Be SAFE booklet}

Evaluating the quality of research through validity and reliability is important to ensure rigor; thus, the findings can be utilized and incorporated in practice [45]. The involvement of experts and representatives of the target audience might elevate the credibility and acceptability of the educational materials. Adapting educational materials to meet the experts' suggestions and recommendations are necessary to make the outcome product more complete, more scientifically rigorous, and thus more effective. It is also an improvement for the material to be validated which in turn helps the quality of future educational materials [46].

\section{Limitations}

Due to logistic limitations on sources and transportation, this research was conducted with a very small percentage of the population in Selangor with the majority of the respondents being of Malay ethnicity with the booklet developed in Bahasa Malaysian only. In future, the booklet will be translated into other languages (English) and may also be distributed across the country.

\section{Conclusion}

The Be SAFE booklet was validated for its content and relevance and was found to be satisfactory and was therefore accepted. The evaluation process included a panel of experts in a related field in education, health, health promotion, or water safety, and representatives 
from the target audience of both parents and guardians. The validated Be SAFE booklet was deemed useful for health education on drowning prevention and water safety for parents/ guardians. Further research is required to determine how the Be SAFE booklet can be used as a guide in improving knowledge, attitude, and practice toward drowning prevention and water safety among parents of primary school children within a local community setting.

\section{4}

\section{References}

1. Saluja G, Brenner R, Morrongiello BA, Haynie D, Rivera M, Cheng TL. The role of supervision in child injury risk: definition, conceptual and measurement issues. Inj Control Saf Promot. 2004; 11(1): $17-22$.

2. Petrass LA, Blitvch JD, Flinch C. Lack of caregiver supervision: a contributing factor in Australian unintentional child drowning deaths, 2000-2009. Med J Aust. 2011; 194(5): 228-31.

3. Simon HK, Tamura T, Colton K. Reported level of supervision of young children while in the bathtub. Ambul Pediatr. 2003; 3(2): 106-8.

4. Moran K. Watching parents, watching Kids: water safety supervision of young children at the beach. Int J Aquat Res Educ. 2010; 4(4): 269-77.

5. Laosee O, Khiewyoo J, Somrongthong R. Drowning risk perceptions among rural guardians: a community-based household survey. Sci Rep. 2013; 2(1): 2-5.

6. Moran K, Stanley T. Parental perceptions of toddler water safety, swimming ability, and swimming lessons. Int J Inj Contr Saf Promot. 2006; 13(3): 139-43.

7. Moran K, Stanley T, Rutherford A. Toddler drowning prevention: teaching parents about child CPR in conjunction with their child's in-water lessons. Int J Aquat Res Educ. 2012; 6(4): 315-24.

8. Moran K, Stanley T, Rutherford A. Toddler drowning prevention: teaching parents about water safety in conjunction with their child's in-water lessons. Int J Aquat Res Educ. 2006; 13(4): 254-6.

9. Amar-Singh H, Pui San T, Lina Hashim. Childhood drowning in Malaysia. Int J Inj Contr Saf Promot. 2014; 21(1): 75-80.

10. Portal rasmi jabatan bomba dan penyelamat Malaysia [internet]. Putrajaya, Malaysia; 2018. Available from: http://www.bomba.gov.my/.

11. Moran K. Re-thinking drowning risk: the role of water safety knowledge, attitudes, and behaviors in the aquatic recreation of New Zealand youth. Palme: Massey University; 2008.

12. McCool J, Ameratunga S, Moran K, Robinson E. Taking a risk perception approach to improving beach swimming safety. Int J Behav Med. 2009 Jan; 16(4): 360-6.

13. Kjendlie P, Stallman R, Olstad B. Water safety education is more than teaching swimming skills: Comprehensive drowning prevention education. World Conference on Drowning Prevention: Danang, Vietnam; 2011.

14. Golob MI, Giles AR, Rich KA. Enhancing the relevance and effectiveness of water safety education for ethnic and racial minorities. Int J Aquat Res Educ. 2013; 7: 39-55.

15. Peden AE, Franklin RC, Scarr J. Measuring Australian children's water SafetyKnowledge: the national water safety quiz. Int J Aqu Res Education. 2017; 10(2): 1-18.

16. Noor Hamzani F, Sutan R, Mani KK. Development and validation of a survey instrument on drowning prevention and water safety among parents of primary school children. J Clin Diagnostic Res. 2019; 13(5): 1-6.

17. Jamshed S. Qualitative research method-interviewing and observation. J Basic Clin Pharm. 2014; 5(4): 87.

18. Deeb A, Suliman S, Tomy M, Yousef H, Rahman LA, Saleh S, et al. Is there a correlation between body weight and awareness of healthy life style components in children? Open J Pediatr. 2015; 5(1): 49-55. 
19. Patti AA, Apostolico AA, Milich LJ, Lewis AG, Murtha AT, Shendell DG. Evaluation of a secondary school cosmetology safety and health training's effectiveness after implementation of a hierarchy of controls "pyramid game" using the "salon safety quiz." J Chem Heal Saf. 2016; 23(6): 16-25.

20. Heale R, Forbes D, Heale R. Understanding triangulation in research. Evid Based Nurs. 2013; 16(4): 101494

21. Spiegel BMR, Talley J, Shekelle P, Agarwal N, Snyder B, Bolus R, et al. Development and validation of a novel patient educational booklet to enhance colonoscopy preparation. Am J Gastroenterol. 2011; 106(5): 875-883A.

22. Teles LMR, Chaves C, Fabiole L, Gomes DS, Oliveira M. Development and validating an educational booklet for childbirth companions. Univ São Paulo Nurs Sch J. 2014; 48(6): 977-84.

23. Joshi HB, Newns N, Stainthorpe A, Macdonagh RP, Keeley FX, Timoney AG. The development and validation of a patient-information booklet on ureteric stents. BJU Int. 2001; 88(4): 329-34.

24. Rahman A, Miah AH, Mashreky SR, Shafinaz S, Linnan M, Rahman F. Initial community response to a childhood drowning prevention programme in a rural setting in Bangladesh. Inj Prev. 2010; 16: 21-5.

25. Sherker S, Williamson A, Hatfield J, Brander R, Hayen A. Beachgoers' beliefs and behaviours in relation to beach flags and rip currents. Accid Anal Prev. 2010; 42(6): 1785-804.

26. Denehy M, Leavy JE, Jancey J, Nimmo L, Crawford G. This Much Water: a qualitative study using behavioural theory to develop a community service video to prevent child drowning in Western Australia. BMJ Open. 2017; 7(7): 1-8.

27. Wilks J, Kanasa H, Pendergast D, Clark K. Beach safety education for primary school children. Int J Inj Contr Saf Promot. 2017; 24(3): 283-92.

28. Oliveira SC de, Lopes MV de O, Fernandes AFC. Development and validation of an educational booklet for healthy eating during pregnancy. Rev Lat Am Enfermagem. 2014; 22(4): 611-20.

29. Iriyani K, Chairunnisa E, Kamba I. Effectiveness of booklet media on mothers ' knowledge and attitude regarding exclusive breastfeeding and breastfeeding practice at Manggar Baru Health Center Balikpapan. Int J Sci Appl Res. 2015; 4531: 11-5.

30. Khurana S, Rao BK, Lewis LES, Bhat R, Purkayastha J, Kamath A, et al. Development and validation of educational leaflet for caregivers of preterm infants. J Clin Diagnostic Res. 2016; 10(7): YC01-4.

31. Nguyen $\mathrm{VH}$. The development and effectiveness of an osteoporosis. Missouri: University of Missouri; 2011.

32. Paul CL, Redman S, Sanson-Fisher RW. Print material content and design: is it relevant to effectiveness? Health Educ Res. 2003; 18(2): 181-90.

33. Short CE, James EL, Plotnikoff RC, Girgis A. Efficacy of tailored-print interventions to promote physical activity: a systematic review of randomised trials. Int J Behav Nutr Phys Act. 2011; 8(1): 113.

34. Hartman SJ, Risica PM, Gans KM, Marcus BH, Eaton CB. Tailored weight loss intervention in obese adults within primary care practice: rationale, design, and methods of Choose to Lose. Contemp Clin Trials. 2014; 38(2): 409-19.

35. Glanz K, Rimer BK, Viswanath K, editors. Health behavior and health education: theory, research, and practice. 4th ed. San Francisco, CA, US: Jossey-Bass; 2018.

36. Lee LK, Thompson KM. Parental survey of beliefs and practices about bathing and water safety and their children: guidance for drowning prevention. Accid Anal Prev. 2007; 39(1): 58-62.

37. Morrongiello BA. Caregiver supervision and child-injury risk: I. Issues in defining and measuring supervision; II. Findings and directions for future research. J Pediatr Psychol. 2005; 30(7): 536-52.

38. Taylor JL. Impact of multiple children on parental supervision practices, parental developmental competence, and unintentional injury risk. Missouri: University of Missouri; 2011.

Water safety and drowning prevention 
39. Gaida FJ, Gaida JE. Infant and toddler drowning in Australia: patterns, risk factors and prevention recommendations. J Paediatr Child Health. 2016; 52(10): 923-7.

40. Bugeja L, Franklin R. Drowning deaths of zero- to five-year-old children in Victorian dams, 19892001. Aust J Rural Health. 2005; 13: 300-8.

41. Naunton M. Near drowning - importance of basic first aid. Croat Med J. 2006; 47: 176-80.

42. An N. Children and drowning in vietnam. Inj Prev. 2012; 18(Suppl 1): A68-9.

43. Hoque DME, Islam MI, Salam SS, Sadeq-Ur Rahman Q, Agrawal P, Rahman A, et al. Impact of first aid on treatment outcomes for non-fatal injuries in rural Bangladesh: findings from an injury and demographic census. Int J Environ Res Public Health. 2017; 14(7): 1-15.

44. Bierens JJ. Handbook on drowning: prevention, rescue, treatment. New York: Springer; 2006.

45. Morse JM, Barrett M, Mayan M, Olson K, Spiers J. Verification strategies for establishing reliability and validity in qualitative research. Int J Qual Methods. 2002; 1(2): 13-22.

46. Lima ACMAC, Bezerra K de C, Sousa DM do N, Rocha J de F, Oriá MOB. Development and validation of a booklet for prevention of vertical (HIV) transmission. Acta Paul Enferm. 2017; 30(2): 181-9.

\section{Corresponding author}

Noor Hamzani Farizan can be contacted at: noor_hamzani@upm.edu.my

For instructions on how to order reprints of this article, please visit our website: 